\title{
The state of financial modelling in 2012, as shaped by the GFC
}

\author{
Rita L. D'Ecclesia
}

Published online: 28 February 2014

(C) Springer-Verlag Berlin Heidelberg 2014

The recent complex dynamics observed in financial and commodity markets require continuous updates, implementation and backtesting of mathematical models aimed to provide an efficient representation of a real world situation.

The aim of the scholars who attended the 50th Meeting of the Euro Working Group for Financial Modelling is to provide "new" tools for, and answers to, the challenges issued by more complex markets dynamics and interactions.

Financial modelling may mean different things to different users; we usually refer either to accounting and corporate finance applications, or to quantitative finance applications.

Recent complex modelling tools have been developed to translate a set of hypotheses about the behaviour of markets or agents into numerical predictions in order to provide effective risk management strategies. The financial crisis which followed the Lehman crash highlighted the need to provide accurate measures of market, credit, operational, liquidity and funding risk measurement and management, for the practitioner and academic world.

Traditional market, credit, operational, liquidity and funding risk measures (including the interplay between them) have to be adequately estimated and monitored by firms, banks and financial intermediaries using proper mathematical models. These models must allow the user to assess the correlated risks and risk concentrations, to implement statistical models for the identification of risks or to run stress-based measures.

Although mathematical modelling and the quantitative approach are clearly important, common sense and an appreciation of a wide range of potential outcomes, includ-

R. L. D'Ecclesia ( $\varangle)$

Department of MEMOTEF, Sapienza University of Rome,

Via del Castro Laurenziano, 9, 00161 Rome, Italy

e-mail: rita.decclesia@uniroma1.it 
ing a willingness to challenge assumptions, are key components for successful financial model development. In this context quantitative models have to be used together with qualitative models. The EWGFM, has been keeping the task of providing a remarkable set of well-known scholars, from academia and the corporate world, sharing their recent studies and findings in the financial modelling area. The participants at the 50th meeting represented the academic and practitioner world, providing a challenging framework for the various experts.

In this volume we collect the most relevant findings presented at the meeting. Novel approaches for portfolio selection strategies and portfolio efficiency were presented by several authors during the meeting. Barro and Canestrelli (2013) tackle the problem of downside protection for investors choosing the optimal investment strategies. They propose a multi-period double tracking error portfolio model which succeeds in maximizing the investor's return and providing downside protection in the case of poorly performing benchmark. They describe the proposed model and test it through a set of out of sample rolling simulations in different market conditions showing how the manager will be able to avoid consistent underperformance of the portfolio. Branda and Kopa (2013) compare various approaches to test the portfolio efficiency. They compare the Data Envelopment Analysis, the Constant Return to Scale DEA, the Second order Stochastic Dominance relation and the Variable Return to Scale DEA models and apply these models to 48 US representative industry portfolios. Their work has been published in Issue 1 of this Volume. Baccarin and Marazzina (2013) propose a portfolio optimization model in presence of fixed transaction costs. They solve the problem using different kind of utility functions and describe how the fixed transaction costs affect the agent's decisions. They also consider the role of the risk aversion and recalibration when setting the optimal strategy.

Some interesting application of the standard option pricing formula in the CEO'management strategies are presented in the paper by Álvarez-Díez et al. (2013). They measure the sensitivity of chief executive officer (CEO) wealth to changes in stock price or stock return volatility using the greeks of the Black and Scholes or the Citvitanic-Wiener-Zapatero (CWZ) models. They show how the use of these greeks could explain the empirical inconsistencies regarding the effect of stock return volatility on executive pay performance sensitivity. They also examine the influence of the firm's stock return volatility on managerial incentives taking into account the impact of investment, diversification and financial policies on both greeks.

The use of market data to analyse and capture important dynamics in financial markets is a common theme amongst several papers in this volume. Castellano and Scaccia (2013) consider single name Credit Default Swap to convey direct information on the occurrence of stock market crises. Using Markov switching model applied to US and European data they show how CDS indexes provide early warning signals of financial distresses in the stock market. Dragotă and Ţilča (2013) analyse the East European stock markets and test the efficient market hypothesis to show that some of these markets are becoming less speculative. They use various kind of EMH tests and show it cannot be rejected for some countries, so that active portfolio management strategies can be set up. Malliaris and Malliaris (2013) provide a novel approach to study the dynamic of the S\&P500 index. They investigate the daily up and down movements for a very long period (from 1950 to 2011) and identify different patterns 
to build conditional forecasts. Using a decision three methodology they are able to show how these forecasts outperform the random walk model. Uberti et al. (2013) analyse the interactions among fixed rate and adjustable rate mortgages in the context of credit markets. They study the entire set of Italian mortgages over the period 19972011 and analyse their changing dynamics. Using an econometric model they capture the switching behavior between the two mortgage markets.

Stochastic optimization models are used to suggest novel pricing models or the optimal use of fossil fuels in the electricity generation process. Bellini and Mercuri (2013) propose a novel model in which the shape parameters evolve according to a GARCH like dynamics. They derive a closed form expression for the characteristic function and therefore for the option price. They test the model using in sample and out of sample data and compare the results to other competing models obtaining very encouraging results. Vespucci et al. (2013) present a single stage stochastic mixed integer linear model which allows to set the optimal technologies mix in the electricity generation process. They use as state variables the fuel prices and introduce as risk measure the Conditional VaR in the objective function in order to take into account for possible losses in the worst case scenarios.

\section{References}

Álvarez-Díez S, Baixauli-Soler JS, Belda-Ruiz M (2013) Are we using the wrong letters? An analysis of executive stock option Greeks. Cent Eur J Oper Res 22(2). doi:10.1007/s10100-013-0287-6

Barro D, Canestrelli E (2013) Downside risk in multiperiod tracking error models. Centr Eur J Oper Res 22(2). doi:10.1007/s10100-013-0290-y

Branda M, Kopa M (2013) On relations between DEA-risk models and stochastic dominance efficiency tests. Cent Eur J Oper Res 22(1):13-35. doi:10.1007/s10100-012-0283-2

Castellano R, Scaccia L (2013) Can CDS indexes signal future turmoils in the stock market? A Markov switching perspective. Cent Eur J Oper Res 22(2). doi:10.1007/s10100-013-0330-7

Dragotă V, Tilča E (2013) Market efficiency of the post communist East European stock markets. Cent Eur J Oper Res 22(2). doi:10.1007/s10100-013-0315-6

Malliaris AG, Malliaris M (2013) N-tuple S\&P patterns across decades, 1950-2011. Cent Eur J Oper Res 22(2). doi:10.1007/s10100-013-0298-3

Baccarin S, Marazzina D (2013) Optimal impulse control of a portfolio with a fixed transaction cost. Cent Eur J Oper Res 22(2). doi:10.1007/s10100-013-0304-9

Bellini F, Mercuri L (2013) Option pricing in a conditional bilateral gamma model. Cent Eur J Oper Res 22(2). doi:10.1007/s10100-013-0286-7

Uberti M, Landini S, Castellina S (2013) Adjustable and fixed interest rates mortgage markets modelling. Evidences from Italy over the last fourteen years. Cent Eur J Oper Res 22(2). doi:10.1007/ s10100-013-0297-4

Vespucci MT, Bertocchi M, Innorta M, Zigrino S (2013) A stochastic model for investments in different technologies for electricity production in the long period. Centr Eur J Oper Res 22(2). doi:10.1007/ s10100-013-0317-4 